\title{
O encontro de Bakhtin e Kagan: fontes filosóficas
}

\author{
Maria Inês Batista Campos ${ }^{1}$
}

\begin{abstract}
Nine years ago, the writings of the Russian philosopher Matvei Kagan were translated from German and Yiddish and arranged for publication in Russia. Vitalij Makhlin published $O$ Khode Istorii [Sobre o curso da história] (2004), a collection of papers and letters that brings the uniqueness of the discussions of the Kantian Seminar in Nevel and Vitebsk, a study circle of great importance to understand the Bakhtinian work. The purpose of this article is to show the main ideas of Kagan having as the starting point the contents of the book and his influence in the fruitful dialogue with Bakhtin identified in some selected letters, in the moment at which his philosophical works were written.
\end{abstract}

Keywords: Philosophy of Language, Kantian Seminar, Phenomenology, Philosophy and History, Correspondence.

Resumo: Há nove anos, os escritos do filósofo russo judeu Matvei Kagan foram traduzidos do alemão e do ídiche e, organizados para publicação na Rússia. Vitalij Makhlin publicou O Khode Istorii [Sobre o curso da história] (2004), uma coletânea de trabalhos e de cartas que trazem a singularidade das discussões do Seminário Kantiano em Nevel e Vitebsk, círculo de estudo de grande importância para se compreender a obra bakhtiniana. O objetivo deste artigo é mostrar as principais ideias de Kagan, partindo do plano da obra e da influência dele nos profícuos diálogos com Bakhtin, identificada em algumas cartas selecionadas, momento em que seus trabalhos filosóficos foram redigidos.

Palavras-chave: Filosofia da linguagem, Seminário Kantiano, Fenomenologia, Filosofia e História, Correspondência.

\footnotetext{
O KHODE ISTORII

De todos os membros do círculo de Nevel, o mais próximo de Bakhtin era Matvei Isaiévitch Kagan. [...] Foi o que mais contribuiu para preencher o claro intelectual e pessoal que a partida de Nikolai abrira. Por ser ligeiramente mais velho e ter um doutorado em filosofia na Alemanha, bem como um certo número de publicações em alemão ligadas a seu nome, atuava como uma espécie de mentor do grupo. ${ }^{2}$
}

1 Professora Doutora do Programa de Pós-Graduação de Filologia e Língua Portuguesa da Universidade de São Paulo; maria.maricamp@gmail.com

2 HOLQUIST, M.; CLARK, K.; Mikhail Bakhtin, 1998. 
É preciso alertar que não se pode avaliar a influência da escola de Marburg sobre Mikhail Bakhtin sem a apresentação dos trabalhos do filósofo Matvej Isaevitch Kagan. ${ }^{3}$

Havia uma pessoa que pude conhecer melhor com o passar do tempo e que virou um dos meus amigos mais íntimos. Ele tinha estudado diretamente na Alemanha, com Hermann Cohen. Morreu há tempo, mas sua filha me visita ainda. É Matvei Isaiévitch Kagan. ${ }^{4}$

\section{Introdução}

A filosofia da linguagem de Mikhail Bakhtin desenvolve-se dentro de uma complexidade de produções filosóficas e sociológicas que não pode ser explicada por um único filósofo isoladamente, mas fruto de uma herança de numerosas obras ${ }^{5}$.

Muitas dessas questões conhecidas nos textos bakhtinianos partem de leituras de filósofos, discutidas durante o Seminário Kantiano realizado entre os anos de 1918 e 1919 na pequena cidade russa de $\mathrm{Nevel}^{6}$. Naquele período, o Círculo de Bakhtin (ainda não tinha esse nome) era constituído por pessoas de várias formações como o linguista Valentin Voloshinov, os especialistas em literatura Lev Pumpianski e Pavel Medeved, a pianista Maria Yudina, o poeta, escultor e arqueólogo Bóris Zubakin e, pelos encontros liderados pelo filósofo Matvei Isaevitch Kagan.

Pesquisadores como o professor russo Nikolaev consideram esse tempo como o mais frutífero da chamada "Escola de Nevel" , por ter contribuído com a formação dos fundamentos de seus membros como, por exemplo, com Bakhtin que, naquele momento, redigiu seus primeiros textos filosóficos: "Arte e responsabilidade" (1919); "Para uma filosofia do ato responsável” (1920-1924); "O autor e a personagem na atividade estética" (1924) ${ }^{8}$. Tais reuniões ocorreram logo após a Revolução Russa (1917), quando os participantes tinham em comum uma paixão pela filosofia idealista alemã "[...] Discutiam várias obras do campo da filosofia, dos antigos gregos até Kant e Hegel"9. O interesse do teórico do dialogismo pela fenomenologia alemã resultou de uma imersão no neokantismo do início do século $\mathrm{XX}$, momento em que conheceu os filósofos de Marburg, principalmente Hermann Cohen, Paul Natorp, Ernst Cassirer por intermédio de Kagan que regressara da Alemanha em 1918.

Neste artigo, o objetivo é mostrar as principais ideias de Kagan, partindo do plano da obra Sobre o curso da história, publicado em Moscou no início do século XXI, e apresentar a influência desse filósofo nos profícuos diálogos com Bakhtin, que pode ser identificada em algumas cartas selecionadas que fazem parte da correspondência inédita presente na obra, momento em que seus trabalhos filosóficos foram redigidos.

3 POOLE, B. Nazad k Kagany, 1995, p. 40.

4 BAKHTIN, M.; DUVAKIN, V. Mikhail Bakhtin em diálogo, 2008, p. 45.

5 Agradecimentos a Craig Brandist que me auxiliou com artigos sobre a obra de Kagan. À professora Denise Sales, pela tradução cuidadosa de boa parte da obra Sobre o curso da história, de Matvei Kagan. E de alguns artigos em russo de Brian Poole citados aqui.

6 Situada a trezentos quilômetros de São Petersburgo, entre a província de Vitebsk e Pskov. A cidade tinha em torno de 10 mil habitantes no início do século XX.

7 NIKOLAEV, N., 1998, p. 29.

8 Sobre a importância da Escola de Nevel para estes escritos filosóficos de Bakhtin, consultar HOLQUIST, M. Introduction: The Architectonics of Answerability. In: HOLQUIST, M.; LIAPUNOV, V.; 1990, p. ix-xliv. Os ensaios filosóficos de Bakhtin escritos neste período foram publicados na Rússia em 1979 e em inglês no livro citado. Em português, Para uma filosofia do ato responsável foi publicado em 2010 por Pedro \& João Editores; parte de "Autor e herói na atividade estética" saiu pela primeira vez em 1992 (Ed. Martins Fontes) na coletânea Estética da criação verbal; "O problema do conteúdo, do material e da forma na criação literária”, publicado em 1988, na coletânea Questões de literatura e de estética: a teoria do romance, Unesp/Hucitec.

9 CLARK, K.; HOLQUIST, M.; 1998, p. 65. 
Desde a década de 1990, as pesquisas realizadas nos arquivos de Bakhtin (documentos escritos, publicação dos primeiros volumes de Obras reunidas) têm permitido penetrar no meio dos densos textos filosóficos que, muitas vezes, resultaram herméticos, tanto pela maneira fragmentada com que eles foram publicados, quanto na falta de conhecimento de muitas referências filosóficas que fazem parte das indicações do Círculo.

Holquist sugere que essa é uma das possibilidades de esses ensaios não serem os favoritos da maioria dos leitores que apreciam Bakhtin, por serem textos extremamente difíceis, exigindo uma erudição dos leitores ${ }^{10}$.

Daí a importância do arquivo que apresentamos a seguir, ainda sem tradução para as línguas ocidentais. Os manuscritos do arquivo pessoal de Kagan, preservados pela família ao longo de 70 anos, foram lançados na Rússia em 2004 e se observa uma cuidadosa coleta de material, resultado do trabalho elaborado pelo pesquisador canadense Brian Poole. Coube a Vitalij Makhlin, professor da Universidade de Moscou, a tarefa de organizar e editar essa documentação, transformando-a no extenso volume com 703 páginas, sob o título O Khode Istorii. (Pedakmop V. L. Makhlin. Iazyki Slavianskoi Kultury: Moscow; [Redator-Organizador V. L. Makhlin. Línguas da cultura eslava: Moscou]).

A obra representa uma contribuição significativa para os estudiosos bakhtinianos que têm a oportunidade de conhecer a produção científica de Matvei Kagan, participante ativo do Círculo de Nevel, e o pensamento filosófico alemão que ele divulgou e com o qual Bakhtin dialogou em muitos momentos na sua obra. O organizador, já na contracapa, esclarece que a edição é "uma tentativa de apresentar o legado de Mikhail Isaevitch Kagan (1889-1937) [...]. Destina-se a todos os que se interessam pela história da filosofia e da cultura intelectual russa do século XX"11. A seguir, o sumário da obra torna-se uma síntese de aspectos biográficos, intelectuais e da correspondência de Kagan.

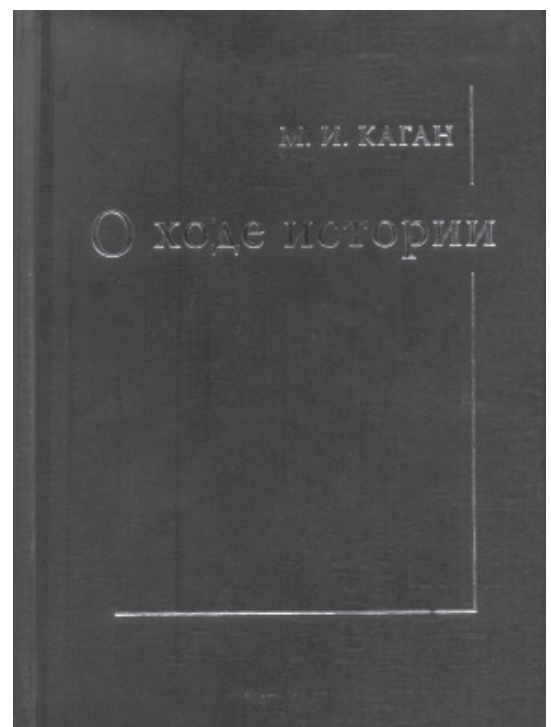

Fig.1: Capa do livro: $O$ Khode Istorii.
М. И. КАГАН

О ХОАЕ ИСТОРИИ

Редактор-составитель B. A. Махиин

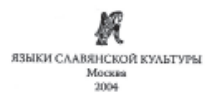

Fig. 2: Folha de rosto: M. I. Kagan. Khode Istorii. Pedakmop V. L. Makhlin. Iazyki Slavianskoi Kultury: Moscow, 2004.

10 HOLQUIST, M., 1990, ix.

11 KAGAN, M. I., 2004, contracapa. 


\section{Sumário}

Introdução do redator

Iudif' Matvei Kagan. "Pessoas não do nosso tempo"

A respeito do autor

Autobiografia 1922

Notas autobiográficas

Biografia científica

Escola Marburg

Hermann Cohen

Hermann Cohen. "Religião da razão de fontes do judaísmo"

Paul Natorp e a crise da cultura

Paul Natorp. "Idealismo social"

\section{Crise}

Ensaio da avaliação sistemática da religião no tempo da guerra $\quad 153$

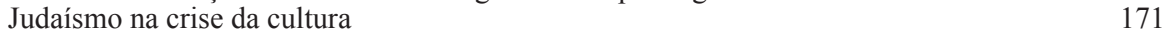

$\begin{array}{ll}\text { Crise da igreja } & 183\end{array}$

$\begin{array}{lr}\text { Sobre a crise religiosa da contemporaneidade } & 187\end{array}$

$\begin{array}{ll}\text { Do almanaque "Dia da arte" } & 191\end{array}$

Filosofia da literatura judaica $\quad 194$

Filosofia da história
os problemas básicos da filosofia da história

$\begin{array}{ll}\text { Como a história é possível? Dos problemas básicos da filosofia da história } & 199 \\ \text { A estática da história } & \end{array}$

No curso da história 238

$\begin{array}{ll}\text { Sobre a compreensão da históriaWW } & 287\end{array}$

Objeto da metodologia da história 308

$\begin{array}{lr}\text { Filosofia e vida } & 309\end{array}$

$\begin{array}{lr}\text { A luta pela história } & 322\end{array}$

Problema da unidade do cotidiano $\quad 333$

$\begin{array}{lr}\text { Problema da individualidade } & 360\end{array}$

Filosofia e história $\quad 368$

$\begin{array}{ll}\text { Cotidiano e o pensamento - história e consciência } & 374\end{array}$

Ciência, filosofia e religião $\quad 385$

Sobre o sentido do amor $\quad 387$

$\begin{array}{ll}\text { A ideia do trabalho } & 390\end{array}$

Sobre o indivíduo na história $\quad 392$

Sobre o indivíduo e a sociologia $\quad 394$

Introdução à filosofia (palestra) $\quad 424$

Monoteísmo e Politeismo $\quad 445$

Introdução e artigo de Kagan nas anotações de Pumpianski $\quad 447$

Filosofia da arte
conteúdo; sem objetividade e com enredo)

$\begin{array}{ll}\text { Duas aspirações da arte (forma e conteúdo; sem objetividade e com enredo) } & 451 \\ \text { Sobre a verdade artística } & 467\end{array}$

$\begin{array}{ll}\text { Sobre o sentido vivo da arte } & 483\end{array}$

$\begin{array}{lr}\text { Sobre a natureza do estilo } & 520\end{array}$

$\begin{array}{ll}\text { Sobre o problema da escultura } & 531\end{array}$

O que é arte?

Sobre a beleza $\quad 545$

$\begin{array}{lr}\text { Sobre a cultura } & 550\end{array}$

Estética de Kant

Enredo $\quad 562$

Arte como reflexo $\quad 565$

Teses do artigo de Spet: "Sobre as fronteiras dos estudos científicos e literários" $\quad 569$

Problema da prosa artística $\quad 573$

Ivan Servei Turgininiev (em homenagem aos 100 anos do escritor) 576

Dúvidas históricas
idealismo histórico

$\begin{array}{ll}\text { Sobre a questão da superação do idealismo histórico } & 585 \\ \text { Motivos dúbios na obra de Púchkin } & 593\end{array}$

$\begin{array}{rr}\text { Motivos dúbios na obra de Púchkin } & 593 \\ \text { Da correspondência } & 629\end{array}$

Notas 671 
Makhlin explica o significado e a importância dos escritos do filósofo aos leitores já na introdução do livro:

O leitor contemporâneo perguntará: Mas quem é este? Outros, que já ouviram ou leram algo em algum lugar, responderão com segurança: foi mais um neokantiano que estudou, na época da Primeira Guerra Mundial, em Marburg, com Cohen e Natorp - e isso é verdade. Aqueles que ouviram e leram um pouco mais acrescentarão: M. I. Kagan, amigo de Bakhtin, participante daquelas discussões em Nevel, em 1918, das quais surgiu a escola filosófica de Nevel (M. I. Bakhtin, M. I. Kagan, L. V. Pumpianski) ou, em outras palavras, o "Círculo de Bakhtin" dos anos de 1920 - o que também é verdade. Mas será que podemos acrescentar alguma outra coisa, mais determinada a esse, na terminologia de Bakhtin, a "fundo dialogizado"? ${ }^{12}$

A obra, dividida em oito partes, começa com dois textos de apresentação: o prefácio, que serve para destacar o sentido da publicação, e o artigo "Pessoas não do nosso tempo", de Iudif Kagan, filha do filósofo, que mostra o percurso das relações partilhadas entre os amigos de Nevel nos encontros frequentes, até o derradeiro reencontro emocionado de seu pai com Bakhtin pouco antes de o filósofo morrer de ataque cardíaco em 26 de dezembro de 1937. Nesse ensaio, o leitor tem acesso a fragmentos de textos originais com uma sinopse e relações estabelecidas por Iudif com o ensaio "Para uma filosofia do ato responsável", de Bakhtin.

Na primeira parte de $O$ Khode Istorii, os textos autobiográficos permitem conhecer um pouco da vida de Kagan por meio da escrita dele mesmo. As cinco partes do núcleo central abrigam aspectos da tradição filosófica - o neokantismo da Escola de Marburg, discussões filosóficas, religiosas, éticas e estéticas. A penúltima seção intitulada "Dúvidas históricas" traz o último ensaio escrito de Kagan, "Motivos dúbios na obra de Púchkin". A importância desse trabalho pode ser atestada na carta escrita por Bakhtin ao editor em 1973, isto é, 36 anos depois da morte do amigo, enfatizando a importância da publicação desse texto.

O trabalho de Matvei Isaevich Kagan é dedicado à análise de poemas do sul, de Púchkin ("O Prisioneiro do Cáucaso", "Os irmãos ladrões", "A fonte da Bakhchisarai", e "Os ciganos"). A análise dos poemas se dá a partir de um ponto de vista original da "perplexidade trágica" que os penetra. Esse ponto de vista, em nossa opinião, foi muito produtivo: ele ajudou a revelar alguns aspectos de significado dos poemas do sul, os quais ainda não encontraram uma compreensão suficientemente profunda na enorme literatura sobre eles. Esse ponto de vista permitiu que M. I. Kagan evitasse os clichês habituais na interpretação dos poemas e aquelas determinadas soluções (convicções ou declarações) que têm sido tantas vezes atribuídas a Púchkin. Pela sua análise bem fundamentada, M. I. Kagan descobre nos quatro poemas a "sabedoria da perplexidade por causa do perigo iminente do amor e da liberdade que a história em si não tem conhecimento, e que é, na melhor das hipóteses, uma fonte de perplexidade". O trabalho de M. I. Kagan, fundamentado completamente na crítica literária, é, ao mesmo tempo, imbuído por um espírito filosófico, que, infelizmente, é tão raramente presente em nossa crítica literária. O trabalho de M. I. Kagan traz uma colaboração refrescante e estimulante. Considero que ele, sem dúvida, mereça ser publicado. Bakhtin, 2/10/1973.13

12 KAGAN, M. I., 2004, p. 7.

13 KAGAN, I., 1992, p. 88. Esta carta pertence ao arquivo da família Kagan. Trad. do russo da Profa. Dra. Fátima Bianchi, Depto de Letras Orientais, Universidade de São Paulo. 


\section{Conexão Letras}

Na parte final, o organizador apresenta "Da correspondência", com cartas que Kagan recebeu dos amigos Bakhtin, Volochinov e outros intelectuais, permitindo que se acompanhe um pouco do cotidiano difícil da vida universitária e do complicado acesso aos livros naqueles tempos soviéticos. Também há referências às dificuldades de Bakhtin para obter alguns livros de filosofia que tratavam de temas-chave postos em discussão pelo amigo Kagan. Trinta páginas de notas finalizam a edição, trazendo informações sobre a circulação e publicação dos artigos.

\section{Quem foi Kagan?}

Segundo Brandist, "o líder do Círculo nos anos de 1920 foi Matvei Kagan, cujos primeiros trabalhos foram sobre a Escola de Marburg". ${ }^{14}$ Ocorre que os primeiros textos escritos por Bakhtin nesse período praticamente só foram descobertos e publicados em 1986, trazendo novos elementos para a compreensão do pensamento filosófico da linguagem dos textos já conhecidos, e, ao mesmo tempo, necessitando de esclarecimentos das fontes e conexões históricas com as principais influências filosóficas. Daí a importância de irmos ao encontro de $\mathrm{Kagan}^{15}$, conhecendo suas atividades filosóficas e sua forte influência no Círculo que por décadas ficou ignorada.

Em Sobre o curso da história, a seção “A respeito do autor" abre o livro com muitas informações significativas. Três textos autobiográficos esboçam a figura do filósofo russo: Autobiografia (1922), Notas autobiográficas (1889-1937), Biografia científica (1925). Autobiografia $^{16}$ é um texto, originalmente escrito a mão em 4 de setembro de 1922, e aparece a seguir traduzido na íntegra. Permite ao leitor percorrer, nas lentes do próprio Kagan, sua vida intelectual e acadêmica, uma vez que ele cita textos produzidos em alemão e publicados em revistas russas especializadas. Foi o ponto de partida que o organizador escolheu explicitar o papel do filósofo e amigo de Bakhtin na transmissão e transformação da tradição filosófica que merece um exame mais detalhado nas outras setecentas páginas.

Nasci em Nevel, na província de Vítebsk. Venho de uma família remediada. Recebi
educação religiosa. Em 1905, terminei o curso no Colégio Popular. Um ano antes
eu havia deixado a escola religiosa russa. Trabalhei durante cinco anos na oficina
de marcenaria e tornearia, tendo terminado o curso com nota máxima. Trabalhei um
ano como aprendiz de um artista pintor. Estava me preparando para entrar na Escola
de Belas-Artes de Odessa, quando, na véspera do exame ${ }^{17}$, fui preso na reunião do
Partido Social-Democrata Russo ${ }^{18}$. Em 1909 , em São Petersburgo, junto ao Comitê
Executivo do Ministério da Instrução Popular, fiz o exame de obtenção do atestado de
maioridade e logo parti para a Alemanha. Entrei para a Faculdade de Filosofia. Estudei

14 BRANDIST, C., 2002, p. 32.

15 Desde o final de 1990, há alguns artigos disponíveis em inglês: KAGAN, I. People no tour time. COATES, R. Two of a small fraternity? Points of contact and departure in the work of Bakhtin and Kagan up to 1924; NIKOLAEV, N. The Nevel School of Philosophy: Bakhtin, Kagan and Pumpianskii between 1918 and 1925: Materials from Pumpianskii's Archives. In.: SHEPHERD, D. The contexts of Bakhtin: philosophy, authorship, aesthetics. Amsterdam: Harwood Academic Press, 1998, p. 3-16; 17-28; 29-42. A correspondência foi publicada pela primeira vez na revista russa, que era inteiramente dedicada a Bakhtin, Dialog. Karnaval. Khronotop. Vitebsk, 1992, 1, p. 60-88.

16 Trad. Denise Sales/UFRGS.

17 Kagan foi preso em 1904 e solto em outubro de 1905.

18 Segundo o formulário pessoal de Kagan de 24/04/1925, ele foi membro do partido de 1904 a 1908. Depois se tornou sem partido. 
em Leipzig (seis semestres), em Berlim (dois semestres) e em Marburg ${ }^{19}$. Disciplina principal: filosofia. Disciplinas secundárias: matemática, história e teoria da arte. Os mestres dos quais sou particularmente devedor foram: de filosofia, Wundt, o jovem Lipps, Riehl, Cohen, Natorp, Cassirer e outros; de matemática, Herglotz, Neumann, Schwarz, Hensel e outros; de teoria e história da arte: Frey e Schmarsow e outros. A minha tese de doutorado versou sobre o tema: Zur Geschichte und Systematik des Problems der transzendentalen Apperzeption ${ }^{20}$. Depois da publicação do doutorado, no Archiv für systematischen Philosophie, em 1916, em Berlim, foi publicado o meu trabalho Versuch einer systematischen Beurteilung der Religion ${ }^{21}$. Concluí e entreguei para publicação em alemão o trabalho Zur Logik der Rechenoperationen mit negativen Zahlen ${ }^{22}$ (infelizmente, não tenho informações sobre o destino deste trabalho). Em russo, tenho os trabalhos: 1) Herman Cohen (publicado no n. 2 de "Nautchnykh Izviéstii" [Notícias da ciência]), 2) "O litchnosti v sotsiologuii" [Sobre a individualidade na sociologia]; 3) "Kak bozmojno istória" [Como é possível a história] (publicado em Orel, Boletim da Universidade de Orel). Agora estou me dedicando a um trabalho em dois volumes sobre filosofia da história e estética (o primeiro estou escrevendo em alemão, o segundo em russo). Passei o período da guerra na Alemanha. Voltei à Rússia em 1917, numa troca de prisioneiros. A partir de 1917, trabalhei em diferentes instituições educativo-culturais. Durante um ano, ocupei a cátedra de filosofia da Universidade Estatal de Orel. Ministrei "Introdução à filosofia" e realizei um seminário de estudo de Platão com atenção especial ao aspecto artístico dos diálogos. No Palácio das Artes, dei palestras ocasionais e o curso "Mitologia do Velho Testamento". Fui e sou membro do Conselho da Cultura Acadêmica Espiritual Livre. Traduzi da língua alemã o livro de P. Natorp Sozial-Idealismus ${ }^{23}$, Berlin, 1921 (entregue à Gosizdat para publicação) Kagan, M. (assinatura). ${ }^{24}$

A lista dos seminários que o pesquisador frequentou permite notar que quase todos os nomes (e não apenas Cohen, Cassirer e Natorp) fazem parte de alguns dos ensaios de Bakhtin e do Círculo como Volkelt, Hamman, Alis Riehl, o eminente Wilhelm Wundt; Georg Mish, autor da história da autobiografia, que exerceu grande influência no ensaio " $\mathrm{O}$ autor e a personagem estética”, de Bakhtin, assim como também a presença do sociólogo Georg Simmel. Os aspectos acadêmicos e as atividades científicas são complementados por Kagan no texto Biografia científica, redigido em Moscou (25/05/1925):

Quase toda a minha atividade científica, desde 1913-14, concentra-se, principalmente, na reelaboração e pesquisa da filosofia em relação à filosofia da história. Com esse intento fundamental da minha atividade, estão relacionados também os meus trabalhos sobre estética, filosofia da arte e crítica de arte. Quase todos os meus trabalhos publicados, escritos e apresentados estão relacionados, de uma forma ou de outra, com meu interesse pela filosofia da história. ${ }^{25}$

19 Kagan menciona os períodos no formulário de 24/04/1925: Leipizig de 1909 a 1914, Berlin de 1911 a 1913 e 1915 a 1918 e Marburg de 1913 a 1915.

20 Segundo o formulário pessoal, Kagan obteve seu título de doutor em filosofia na Universidade de Marburg onde estudou, segundo esse documento, de 1909-1914. Em port. "Para a história e a sistemática da apercepção transcendental".

21 Em port. "Tentativa de uma avaliação sistemática da religião".

22 Em port. "Para a lógica das operações aritméticas com números negativos".

23 Vale destacar as notas apresentadas por Tylkowski a esse texto, devido ao acesso aos arquivos russos. Ela menciona que "a ausência deste título nos catálogos das bibliotecas permitem pensar que ele jamais viu o dia" (TYLKOWSKI, I., 2012, p. 258).

24 KAGAN, M. I., 2004, p. 23.

25 KAGAN, M. I., 2004, p. 28-29. 


\section{Conexão Letras}

Quanto às informações filosóficas em torno de Kagan, a partir da década de 1990, estudiosos como Poole (1995), David Shepherd, Ken Hirschkop (1999), Galin Tihanov (2000), Craig Brandist (2002), passaram a enfatizar a importância da filosofia e da estética idealista alemãs como base do pensamento de Bakhtin e retomaram o encontro de Bakhtin com Kagan. Cada um deles, no entanto, assinala posições diferentes sobre essa presença ${ }^{26}$ e, hoje, outros pesquisadores se unem a esse coro filosófico, ressaltando sua importância fundamental para os estudos bakhtinianos e para esclarecer a noção do dialogismo ${ }^{27}$.

\section{3 À porta da Escola de Marburg: o caminho da filosofia}

O livro Sobre o curso da história traz o título homônimo de um dos mais importantes artigos de Kagan, que discute os conceitos de cultura, valor, conhecimento e amor, questões particularmente consideradas na teoria bakhtiniana. Para compreender este curso da história, afirma o filósofo, é necessário compreender que "O sistema do ser histórico está sempre aberto, é um vir-a-ser. Fora do processo histórico, o ser humano é impensável. De acordo com esse objetivo, haverá diferentes direções no interior do processo". ${ }^{28} \mathrm{E}$ no ensaio "Sobre o curso da História", o filósofo defende sua posição: "Outra vez e outra vez nós começamos a viver historicamente. Esse é o processo para abrir constantemente possibilidades renovadas [...] Na realidade, a história está sempre começando" ${ }^{29}$.

Makhlin situa o leitor no que concerne ao pensamento de Kagan, elegendo quatro temas centrais do material organizado, destacados no sumário. Eles foram produzidos, na sua maioria, no período entre 1919 e 1925: "Escola de Marburg", "Crise", "Filosofia da história", "Filosofia da arte". Nota-se que tal distribuição se ocupa de conceitos-chave dos estudos filosóficos e, muitos estão presentes na obra do Círculo de Bakhtin.

O título da segunda parte da obra é "Escola de Marburg", reunindo quatro ensaios que tratam de dois grandes nomes que resumem a história dessa Escola que teve uma vida ativa longa por quase 50 anos: Hermann Cohen (4/7/1842- 4/4/1918) e Paul Natorp (1854-1924). Os dois primeiros ensaios foram sobre seu orientador, Hermann Cohen ${ }^{30}$, o primeiro foi escrito após a morte dele em 1918, e publicado em 1922, no periódico Nautchnye Izvestiia. Shornik vtoroi (Moscow: Akademicheskii tsentr Narkomprosa) [Notícias científicas]. Muitos aspectos da filosofia neokantiana de Cohen e sobre a ética e a estética estão apresentados no texto; "Hermann Cohen: Religião da razão de fontes do judaísmo" foi o segundo texto escrito em 1920 ou 1921 (sem indicação precisa de data). Há um ensaio intitulado "Paul Natorp e a crise da cultura", publicado em Moscou em 1922 e a tradução para o russo do ensaio de Paul Natorp "Idealismo social" (1920), em 1922, com "as ideias de fraternidade, aprendizagem, infinita abertura da história e as suas tarefas, a energia de produtividade cultural" 31 .

A terceira parte "Crise", como sugere o título, discute temas ligados a problemas religiosos, um dos pivôs da obra de Kagan, com questões relativas ao ser histórico, a permanente oposição da realidade: imanência e transcendência. Seis artigos estão reunidos

26 KASTMAN, R., 2013, p. 9.

27 Ver BUBNOVA, T. El principio ético como fundamento del dialogismo en Mijaíl Bajtin. In.: La palabra,

Tunja, Boyacá, Colômbia, 1995, nº 4 e 5, p. 9-16.

28 KAGAN, I., 1998, p.11.

29 Idem, p. 11.

30 Este ensaio está traduzido para o inglês por Brandist e Shepherd. In: BRANDIST, C.; SHEPHERD, D; TIHANOV, G., 2004, p. 193.

31 KAGAN, M. I., 2004, p. 110-114. 
aí: "Ensaio da avaliação sistemática da religião no tempo da guerra" (1916); "Judaísmo na crise da cultura" (1923, publicado em 1988), "Crise da igreja", "Sobre a crise religiosa da contemporaneidade", Do almanaque "Dia da arte", "Filosofia da literatura judaica". Seu engajamento no movimento intelectual interessado no judaísmo e sua herança podem ser comprovados também nas muitas conferências que deu em instituições fundadas para estudar o legado do povo israelita como a Universidade Nacional Judaica de Moscou e a Universidade Judaica de Petrogrado.

A quarta parte, intitulada "Filosofia da história", congrega 19 ensaios, tornando-se o conjunto mais extenso da obra, o que demostra ser um dos eixos mais significativos do pensamento filosófico de Kagan. "Como a história é possível?" Dos problemas básicos da filosofia da história, publicado em 1921 nos Anais da Universidade Estatal de Orel; "A estática da história"; "No curso da história" (1920); "Sobre a compreensão da história"; "Objeto da metodologia da história"; "Filosofia e vida"; "A luta pela história"; "Problema da unidade do cotidiano"; "Problema da individualidade"; "Filosofia e história"; "Cotidiano e o pensamento: história e consciência"; "Ciência, filosofia e religião"; "Sobre o sentido do amor"; "A ideia do trabalho"; "Sobre o indivíduo na história"; "Sobre o indivíduo e a sociologia"; "Introdução à filosofia" (palestra); "Monoteísmo e politeísmo"; "Introdução e artigo de Kagan nas anotações de Pumpianski".

Desse conjunto da "Filosofia da história", alguns pesquisadores sugerem que há uma trilogia de artigos que provavelmente influenciou textos de Bakhtin. Os artigos são: "O lichnosti v sotsiologii" ("Sobre o indivíduo da sociologia" [1918-19]), "Kak vozmozhna istoriya?"; ("Como a história é possível?" [1919]); 'O khode istorii”" ("No curso da história" [1920]).

A quinta parte, sob o título de "Filosofia da arte", reúne quatorze artigos: "Duas aspirações da arte" (forma e conteúdo; sem objetividade e com enredo) [set.-nov. 1922], "Sobre o sentido vivo da arte"; "Sobre a natureza do estilo"; "Sobre o problema da escultura" (manuscrito sem data/1922-1924); "O que é arte? (Teses desenvolvidas na palestra 11/12/1921?)"; "Sobre a beleza", manuscrito sem data/artigo para dicionário de estética; "Sobre a cultura"; "Estética de Kant", "Enredo"; "Arte como reflexo"; Teses do artigo de Spet: "Sobre as fronteiras dos estudos científicos e literários", Spet escreveu para as reuniões filosóficas; "Problema da prosa artística" texto lido em 23 de outubro de 1923, na reunião da seção filosófica da Academia estatal de ciências artísticas); "Ivan Servei Turgininiev", texto em homenagem aos 100 anos do escritor, escrito em í́diche.

Em "Duas aspirações de arte", traz as ideias de Ernst Cassirer. Esse filósofo marcou profundamente o pensamento do Círculo: Voloshinov traduziu o volume 1 da A filosofia das trocas simbólicas, "A linguagem". Teve uma influência importante em duas obras de Bakhtin: "A cultura popular na idade média e no renascimento" e seu estudo sobre Goethe e o Bildungsroman, incluindo o ensaio sobre o cronotopo.

\section{Diálogos possíveis entre Bakhtin e Kagan: as cartas}

Vitali Makhlin compilou várias cartas que Kagan recebeu de intelectuais como Gustav $\operatorname{Spet}^{32}$ (1), Voloshinov (1), R. Mejelaia (1), A. Berdiáev (1) ${ }^{33}$. Sem dúvida, foi M.

32 Gustav Spet (1879-1937), filósofo russo, psicólogo, crítico de arte, tradutor. Discípulo de Husserl, foi membro do Círculo linguístico de Moscou e formulou a ideia da filosofia positiva e trabalha sobre problemas da lógica, fenomenologia, semiótica, hermenêutica, poética e filosofia da linguagem.

33 Nikolai Alexandrovich Berdiaev (1874-1948), filósofo russo ucraniano, participante da Academia Livre de Cultura Espiritual de Moscou, com perspectivas existencialistas. Morreu em Paris (informações baseadas nas notas do livro). 


\section{Conexão Letras}

Bakhtin que manteve com o amigo uma presença constante durante um ano, contabilizando nove cartas entre 20 de fevereiro de 1921 a 18 de janeiro de 1922. A maioria delas é curta, não traz o local onde foram escritas, mas são muito interessantes pelos comentários que trazem sobre filosofia e as referências a seus projetos filosóficos. Há relatos de questões referentes à sua saúde difícil, tentativa de arrumar emprego, como também procura saber notícias do amigo, tentando animá-lo nos trabalhos junto à complexa burocracia soviética.

Pela correspondência, podemos recompor alguns projetos com os quais Bakhtin estava comprometido na década de 1920, texto entremeado de relatos pessoais e o convite para que Kagan participe do casamento dele em 10 de julho de 1921. Em 20 de fevereiro de 1921, por exemplo, merece destaque a carta que menciona a elaboração do livro Estética da criatividade verbal, porque "sete meses depois, em agosto de 1922, a revista de Petrogrado, $A$ vida da arte, afirmava que Bakhtin havia concluído um livro sobre Dostoiévski e uma monografia intitulada $A$ estética da Criatividade Verbal"34. Aconteceu-me mais uma desgraça: em virtude da complicação após o tifo, surgiu
uma inflamação na medula óssea da perna direita, foi preciso fazer uma operação,
e agora estou numa cama de hospital; devo ficar em repouso provavelmente ainda
umas duas semaninhas. [...] Em Vítebsk, não me sinto nada bem, passo quase o
tempo todo na cama, quero muito sair daqui o mais rapidamente possível. Tente,
meu querido, fazer tudo o que puder para mim em Orel e escreva em detalhes como
andam as coisas e quais são as condições de vida em Orel. Como estão as suas aulas
e os seus negócios em geral? Em que está trabalhando agora? Nos últimos tempos,
tenho trabalhado quase exclusivamente na Estética da criatividade verbal. Espero
que logo possamos conversar pessoalmente. Perdoe-me se escrevo pouco, a lápis,
em garranchos, mas escrever deitado é muito difícil. Um beijo,

Seu M. Bakhtin ${ }^{35}$

Entre outubro e novembro de 1921, Bakhtin escreveu ao amigo pedindo-lhe uma importante contribuição bibliográfica, uma vez que estava empenhado em desenvolver seu projeto sobre a filosofia da moral. Se voltarmos a um dos seus primeiros ensaios filosóficos "O autor e a personagem na atividade estética" é possível identificar uma influência dessa leitura neokantiana. Ao desenvolver sua proposta estética, uma fonte marcante é Hermann Cohen, que tinha publicado em 1912 Estética do sentimento puro como parte final de seu sistema de filosofia, ou seja, apenas uma década antes de Bakhtin ter escrito seu texto. Esse interesse está perceptível na carta:

Comecei um trabalho que agora tenho intenção de terminar - "O sujeito da moral e o sujeito do direito". Em breve pretendo dar a esse trabalho uma forma definitiva e completa; ele servirá de introdução à minha filosofia da moral. Mas, para terminá-lo, é imprescindível a "Ética" de Cohen. ${ }^{36}$ Será que o senhor, caro Matvei Issaevitch, poderia consegui-lo de alguma forma em Moscou e enviá-lo para mim no menor prazo possível? Eu lhe seria imensamente grato. Pode ser que encontre também Kants Begründung der Ethik [Justificativa de Kant em torno da ética] ${ }^{37}$. Talvez o senhor possa achar ainda algum outro material sobre questões do direito e da moral (aliás,

34 CLARK, K.; HOLQUIST, M., 1998, p. 79.

35 KAGAN, M. I., 2004, p. 631.

36 COHEN, H. Ethik des reinen Willens (Ética da vontade pura). Berlin. Bruno Cassirer, 2. Aufl. 1907. (N. O.)

37 COHEN, H. Kants Begründung der Ethik (Justificativa de Kant em torno da ética) 2. verbessert und erweiterte Auflage. Berlim: Bruno Cassirer, 1910. (N. O.) 
Ivan Ilin estudou em especial essa questão ${ }^{38}$ ). Em Vítebsk ${ }^{39}$ não há absolutamente nada, e isso dificulta muito o meu trabalho. Pelo amor de Deus, Matvei Issaevitch, descubra alguma coisa e envie-a para mim, ocasião facilmente se encontrará, além disso, é possível remeter também pelo correio. Ser-lhe-ei imensamente grato. [...] Val[entin] Nik[olaevitch] e Olga Mikh[ailovna] mandam lembranças.

Um beijo, Seu M. Bakhtin ${ }^{40}$

Os temas discutidos por Kagan em vários de seus artigos como "Paul Natorp e a crise da cultura", "O idealismo social", "Hermann Cohen", a tradução do texto de Hermann Cohen, "Religião da razão nas fontes do judaísmo" tratando das categorias temporais e das ideias éticas do filósofo de Marburg, são discussões filosóficas presentes nos textos de A filosofia do ato, no Autor e a personagem na atividade estética, O discurso no romance (1934-1935) e "O romance de educação e sua importância na história do realismo" (1936-1938).

A correspondência avança mês a mês, a saúde de Bakhtin melhora e depois de um ano ele traça novos projetos: na carta de 18 de janeiro de 1922, discute sobre a redação de seu artigo em torno de Dostoiévski e indica que o texto sobre "O sujeito na vida moral e o sujeito na lei" estava sendo deixado de lado. Também demonstra entusiasmo com as possibilidades de publicação dos textos de Kagan.

Querido Matvei Issáevitch, por que do senhor não chega nenhum sinal de vida? [...] Vl[adimir] Al[eksandrovitch] Vei[kchan?] chegou há pouco de Moscou e disse que o senhor está vivo, com saúde, trabalhando na Academia de Cultura Espiritual. Mando esta carta por ele. Minha saúde agora está completamente restabelecida e tenho trabalhado muito; a vida material não anda mal, alimento-me perfeitamente bem, estou engordando e dedico muito tempo a trabalhos extras. Agora estou escrevendo sobre Dostoievski e espero terminar muito em breve; "O sujeito da vida moral e o sujeito na lei" por enquanto deixei de lado. Tenho informações bem detalhadas sobre Liev Vassílevitch: arranjou-se muito bem em Petrogrado; como professor, tem moradia e alimentação garantidas, trabalha muito; nos próximos dias deve sair, aliás, provavelmente já saiu, o seu trabalho sobre Romain Rolland e sobre Gógol; a propósito, tudo isso será publicado nas condições mais vantajosas - quais são elas exatamente eu não sei em detalhes. Além disso, ele já combinou a publicação de suas palestras sobre filosofia natural em Berlim (em russo), com um representante da editora berlinense na Rússia. Em geral, pelas notícias que tenho, em Petrogrado publica-se com facilidade e em condições vantajosas. [...] Um beijo, Seu M. Bakhtin. ${ }^{41}$

As cartas demostram o quanto Kagan esteve ao lado de Bakhtin auxiliando-o a tentar conseguir um posto de trabalho em Orel ou Moscou, por exemplo, mas a doença não the permitiu assumir o cargo. O sonho de deixar Vitebsk era muito grande, mas a realidade vem narrada na correspondência selecionada de março de 1921 e de 30 de setembro de 1921:

[...] Infelizmente, eu não posso viajar logo, terei de ficar mais um pouco, já que a doença na perna está sarando; na verdade já saí da cama, mas me movimento com dificuldade, e o ferimento ainda não cicatrizou. Poderei viajar apenas daqui a umas

38 Ivan Alekssándrovitch Ilin (1882-1954). Professor da Universidade de Moscou, exilado em 1922. Filósofo, aluno de P. I. Novgorodtsiev. A partir de 1910, foi influenciado por Edmund Husserl e Hermann Cohen e também pelas então recentes correntes do intuitivismo e do renascimento hegeliano na Alemanha. (N. O.)

39 Cidade na região dos lagos glaciários, atualmente em território bielorrusso. (N. T.)

40 KAGAN, M. I., 2004, p. 636-637.

41 KAGAN, M. I., 2004, p. 638. 
duas, três semanas, porém, seja como for, não depois de 10 de abril. Informe à Universidade, querido Matvei Issáevitch, sobre a minha demora. Acredito que o meu atraso não estragará as coisas, não é?

Escreva-me também: o que exatamente a Universidade de Orel entende por "cátedra de história da língua russa. [...] Um beijo, Seu M. Bakhtin? ${ }^{42}$

[...] Seria bom se alguma instituição de Moscou (talvez o Centro Acadêmico) me chamasse para algum tipo de negociação: isso facilitaria aqui a obtenção de passagens de graça. [...] O nosso sonho, de Elena Alekssándrovna e meu, é morar junto com o senhor não só na mesma cidade, mas sob o mesmo teto. Talvez ele se concretize? [...] Um beijo, Seu M. Bakhtin ${ }^{43}$

A correspondência mantida nos arquivos da família de Kagan permite mostrar o quanto os dois filósofos caminharam juntos, mesmo sem ter partilhado o mesmo teto. No ensaio de 1995 em torno da influência de Kagan sobre a Escola de Marburg e a filosofia de Bakhtin, Brian Poole recupera o texto "Sobre o sentido vivo da arte", em que Kagan apresenta a noção de Natorp em torno da arte e da vida (1924) e como ela está presente na obra de Bakhtin, principalmente em A cultura popular na Idade Média e no Renascimento.

O intervalo, a pausa da vida e do trabalho do gênero humano no descanso para uma nova vida do trabalho e do gênero da humanidade, não é tomado apenas como um simples intervalo, como uma pausa mortal vazia. Ele deve ser pleno de novas tarefas de vida e de trabalho da humanidade. E apenas por enquanto essa nova tarefa ainda não está viva ou, uma vez que na antiga vida do trabalho antiga do gênero humano a incompletude não pode ser aceita de modo algum, essa pausa vive, conservando o antigo. O descanso no intervalo da busca eterna pelo novo e pela nova fundação do trabalho da vida, a pausa e $o$ trégua do constante fruto e nascimento criativo ativo de uma vida viva cada vez mais nova do gênero humano não é um lugar vazio; se ele não é apenas o fenômeno do trabalho e não é apenas o fenômeno do nascimento da vida, então, ainda assim, ele não é supérfluo naquilo que conserva dentro de si. A arte conserva o trabalho passado e o gênero humano e conserva em si as possibilidades de trabalho futuro e da vida futura do gênero humano. ${ }^{44}$

\section{Considerações finais}

Sobre o curso da história, de Kagan, não é somente uma coletânea de artigos e correspondências inéditas de um filósofo russo que foi ignorado por muito tempo tanto na Rússia quanto no Ocidente e que ainda hoje não ganhou a atenção da maioria dos estudiosos de Bakhtin. Essa obra torna-se uma porta de entrada para uma aproximação à complexa filosofia da linguagem de Bakhtin, porque traz textos significativos para a compreensão de conceitos filosóficos da Escola de Marburg.

Os diálogos presentes nas cartas emergem nos primeiros ensaios de Bakhtin, quando a questão estética é tratada não como um conceito mecânico e abstrato, mas a partir de uma compreensão do ser humano que vive durante certo tempo e espaço. A interpretação do ato estético se dá a partir de uma compreensão filosófica que sustenta, no fundo, todo

42 KAGAN, M. I., 2004, p. 631.

43 KAGAN, M. I., 2004, p. 635.

44 POOLE, B., 1995, p.43. 
seu pensamento e tem bases nas questões discutidas por Kagan na resenha feita do livro de Hermann Cohen A religião da razão:

O tempo transforma-se em futuro e apenas futuro. Assim, para a vida do ser humano e do povo, surge a ideia da história. Para a vida do ser humano e do povo, surge a ideia da história. Essa noção de história os gregos não tinham. A história dos gregos estava orientada para a narrativa do passado da nação grega ${ }^{45}$

A contribuição de Makhin nesta organização e de Poole em recolher todo este acervo é fundamental para todos aqueles que buscam as fontes filosóficas, porque nos mostra que Kagan escreveu em tempos difíceis da União Soviética sob o domínio de Stálin, e mesmo assim não deixou de ensinar nas várias universidades, nem de manter longas conversas com os colegas. Com Bakhtin, ele voltou para o último encontro.

\section{Referências}

BAKHTIN, M. M. O problema do conteúdo, do material e da forma na criação literária. In: Questões de literatura e de estética: A teoria do romance.. São Paulo: Hucitec, 1998, p. 13-70. Trad. Aurora F. Bernadini et al.

. O autor e a personagem na atividade estética. In: Estética da criação verbal. . São Paulo: Martins Fontes, 2003, p. 3-192. Trad. Paulo Bezerra

. Para uma filosofia do ato responsável. São Carlos: Pedro \& João Editores, 2010. Trad. Valdemir Miotello e Carlos Alberto Faraco.

BAKHTIN, M.; DUVAKIN, V. Mikhail Bakhtin em diálogo: conversas de 1973 com Viktor Duvakin. São Carlos: Pedro \& João Editores, 2008.

BRANDIST, C.; SHEPHERD, D.; TIHANOV, G. (ed.). The Bakhtin Circle In The Master's Absence. Oxford: Manchester University Press, 2004.

BUBNOVA, T. El principio ético como fundamento del dialogismo en Mijaíl Bajtin. In: La palabra, Universidad Pedagógica y Tecnológica de Colombia, Tunja, Boyacá, Colômbia, 1995, n$^{\circ} 4$ e 5, p. 9-16.

CLARK, K. \& HOLQUIST, M. Mikhail Bakhtin.. São Paulo: Perspectiva, 1998. Trad. J. Guinsburg

COATES, R. Two of a Small Fraternity? Points of Contact and Departure in the Work of Bakhtin and Kagan up to 1924. In: SHEPHERD, D. (ed.). The Contexts of Bakhtin: Philosophy, Authorship, Aesthetics. Amsterdam: Harwood Academic Publishers, 1998, p. 17-28. Translated by. Vadim Liapunov

HOLQUIST, M.; LIAPUNOV, V. The Architectonics of Answerability: Early Philosophical Essays by M.M. Bakhtin.. Austin: University of Texas Press, 1990.

KAGAN, I. O starykh bumagakh iz semejnogo arkhiva: M. M. Bakhtin. Dialog, Karnaval, Khronotop, 1992, I: 60-88.

. People no tour time. In: SHEPHERD, D. (ed.). The Contexts of Bakhtin: Philosophy, Authorship, Aesthetics. Amsterdam: Harwood Academic Publishers, 1998, p. 3-16. KAGAN, M. I. Hermann Cohen. In: BRANDIST, C.; SHEPHERD, D.; TIHANOV, G. (ed.). The Bakhtin Circle In The Master's Absence. Oxford: Manchester University Press, 2004, p. 193-211. 
O khode istorii. Ed. Vitalij Makhlin. Moscow: Jazyki slavianskoi Kultury, 2004. KATSMAN, R. Love and Bewilderment: Matvei Kagan's literary Critical Concepts. Partial answers 11/1: 9-28, 2013, The Johns Hopkins University Press.

NIKOLAEV, N. The Nevel School of Philosophy (Bakhtin, Kagan, and Pumpiansky) Between 1918 and 1925: Materials from Pumpianskii's Archives. In: SHEPHERD, D. (ed.). The Contexts of Bakhtin: Philosophy, Authorship, Aesthetics. Amsterdam: Harwood Academic Publishers, 1998, p. 29-42.

- Lev Pumpianskii and the Nevel School of Philosophy. In: BRANDIST, C.; SHEPHERD, D.; TIHANOV, G. (ed.). The Bakhtin Circle In the Master's Absence. Oxford: Manchester University Press, 2004. p. 125-49.

POOLE, B. Nazad k Kaganu. In: Dialog, Karnaval, Khronotop. n. 1, 1995, p. 38-48. STEINBY, L. Hermann Cohen and Bakhtin's early aesthetics. In: Stud East Eur Thought. Pubhished online. Springer Science, 2011, 63: p. 227-249. Disponível em: http://www.deepdyve.com/lp/springer-journals/hermann-cohen-and-bakhtin-s-early-aesthetics-yhMLSzGj5y. Acesso em: 10.01.2011.

TYLKOWSKI, I. Vološinov en contexte: essai d'épistémologie historique. Limoges, Lambert-Lucas, 2012, p. 257-259. 